\title{
correspondence
}

\section{Is anonymity necessary?}

SIR,-As co-editor of a series of books (Comprehensive Virology, Plenum, 1974) I was recently taken to task concerning the advisability of anonymous reviewing of solicited chapters. We fully agree with this criticism and will in the future request our reviewers to submit their constructive critical comments over their signature, so that the author can ask for clarification or defend his position.

As a past or present member of the editorial boards of several journals as well as frequent reviewer and reviewee of papers, I would like to broaden this enquiry into the effect of anonymity in the domain of reviewing for scientific journals. I was recently asked to review, and advocated rejection of, a paper for a virological journal on the basis of factual comments which I would have been quite willing to sign. The editor sent me, out of courtesy, copies of his rejection letter together with the other reviewer's sarcastic poison-pen comments, also rejecting the paper. There was no justification for one civilised person insulting another in such manner (as well as a specified alternative "boring" journal that might be willing to publish such "routine and dull work"); that outburst was solely the joy of releasing adrenaline with anonymous impunity.

I have read many other reviews which were full of bias. In one recent instance the reviewer, not wishing to accept the well proven conclusion of the author, misquoted the literature to prove his point to an editor who would not have the time to verify his citations.

I have given this matter considerable thought. There is no question that much good comes out of careful and conscientious reviewing and that scientific communication would not be improved by abolishing it altogether. But anonymity tends to bring out the worst in people and it causes undesirable aspects of the reviewing system which I believe to be unnecessary. Thus I advocate that editorial boards could and should come out strongly in favour of reviewers identifying themselves when they detect factual errors, weaknesses in the argument, inadequate or erroneous citations, or lack of clarity in a manuscript. The author can then consider these comments in the same polite and considerate style that such reviews would show.

This suggestion does not preclude the reviewer expressing his conclusions di- rectly to the editors if he feels this to be necessary or helpful. If he advocates rejection in his letter to the editor, and if this is supported by the factual arguments given to the authors which in turn are not easily and clearly countered by them, then the scientific level of the journal would not be diminished, and the state of mind of the scientific community would be noticeably improved. Yours faithfully

Heinz Fraenkel-Conrat

Department of Molecular Biology

and Virus Laboratory,

University of California,

Berkeley, California 94706

\section{Protein Gap}

SIR,-The Food and Agriculture Organisation of the United Nations and the World Health Organisation have just published jointly their latest report on energy and protein requirements of man based on a comprehensive review of 50 years research in the field. A comparison of the average requirements per person based on this report ${ }^{1}$ with average intakes shows that there is no protein gap at the national level. In most countries the average protein intake exceeds the average requirement so considerably that inequality in the consumption also fails to explain the full extent of the incidence of protein malnutrition. Furthermore, in those few individuals whose protein intake is found to be inadequate, the deficiency of energy intake relative to requirement is even more marked. Clearly, what diets lack is not protein but energy to metabolise the protein people actually eat ${ }^{2,3}$ (Miller and Payne, 1969; Sukhatme, 1969). In the circumstances the United Nations call to intensify production of semi-conventional protein-rich foods for closing the so-called protein gap seems to have little to commend it to the developing countries (U.N. General Assembly Resolution 1970).

Surprisingly, however, the 1973 report incorporates a new interpretation of the meaning of protein requirement to help planners evaluate an apparently non-existent protein gap. This interpretation is that an individual eating below the recommended level, called a 'safe' level in the report (that is the average requirement plus twice the standard deviation), while not necessarily malnourished, runs the risk of developing protein deficiency and that the risk increases as the intake falls below the "safe" level.
The implication is that individuals should be counselled to eat at levels above the "safe" level and that countries should aim to increase their protein supplies to make this possible. Calculations based on the normal bivariate distribution model for intake and requirement, which is implicit in the new interpretation of requirement show that the needed increases are very large; so large in fact as to be considered "unrealistic of the situation in the developing countries" 4 . In effect this exercise implies that $97.5 \%$ of the population would have to eat at levels of overconsumption-or waste-several times greater than the average needs to limit the population at risk (that is below the "safe" level) to $2.5 \%$. If it were not protein but some other nutrient, say Vitamin A, these levels would be in the toxic range!

Evidently the assumptions implicit in the new interpretation of requirement require careful evaluation. I have examined them and find that they are not supported by available data. In particular, I find that the basic assumption that the requirement of an individual, like his intake, is known and can be determined with an error of mcasurement which can be assumed to be negligible, is not borne out by the data. I find that intra-individual variability in requirement often accounts for a major part of the total variation. Consequently neglecting to take it into account gives a grossly exaggerated and misleading picture of the protein problem in the countries concerned. In a similar vein, such statements as "two-thirds of the world is hungry and malnourished" as was first suggested by Lord Boyd Orr and which continue to be repeated in evaluating the nutritional situation in the developing countries have their origin primarily in the failure to recognise the status of the variable quantified by requirement. Details will be found in Sukhatme 5,6 .

Yours faithfully, P. V. SukHatme

Department of Statistics,

University of Edinburgh

1 WHO, Energy and Protein Requirements 522, (Geneva, 1973).

2 Miller, D. S., and Payne, P. R., Proc. Nutr. Soc., 28, 225 (1969).

${ }^{3}$ Sukhatme, P. V., Indian J. med. Res. New Delhi, 57, 2170 (1969).

4 Beaton, G. H.. Proc. Western Hemisphere Nati. Congress, (Miami, 1972).

5 Sukhatme, P. V., J. Roy. Stat. Soc. Series $A$ (in the press).

${ }^{6}$ Sukhatme, P. V., Proc. Nutr. Society, 33, 36A (1974). 